\title{
Study on Evaluation Criteria of Chinese Comic Dialogues and Sketches based on Principles of Discourse Construction
}

\author{
Hongmei TANG ${ }^{1,2}$, Jun ZHANG ${ }^{2}$ \\ ${ }^{1}$ Faculty of Arts, Communication University of China, Beijing, China, 100021 \\ ${ }^{2}$ Anhui University of Science and Technology, Huainan, China, 232001
}

\begin{abstract}
Chinese Comic Dialogues and sketches(CCDS for short) now play very important roles in people's spiritual lives. Aiming at the phenomenon that some sketches are popular and welcome at home yet questioned abroad, this article analyzes, gives the criteria of Chinese Comic Dialogues and sketches based on Principles of Discourse Construction The article emphasizes that actors should not satirize the disabled and the mentally disordered, sing the praises for swindlers, perform the obscene pieces and also cannot make unhealthy tendencies and evil influences of society etc, otherwise, the performance is vulgar. "Situationality" is in having different works corresponding to different occasions or different audiences. "Acceptability" is in the audience's satisfaction with performances. The acceptability is a sufficient condition yet not a necessary condition. Therefore, proceeding from promoting the harmonious development of Chinese society, the evaluation criteria of CCDS are: the performances should win the applause of vast spectators, and the content must be positive and progressive as well.
\end{abstract}

KEYWORD: Chinese Comic Dialogues (CCD); Sketches; the Principles of Discourse Construction; Evaluation Criteria

\section{INTRODUCTION}

Chinese Comic Dialogues (CCD) and sketches is one of the quyi ( Chinese folk art forms; including ballad singing, storytelling, comic dialogues, clapper talks, cross talks, etc) which are welcomed by the Chinese audiences most. Among them, CCD was formed and produced in the last phase of Qing dynasty in Beijing. It affects the whole nation and so far it has had a history of more than a hundred years. $\mathrm{CCD}$, originating from joke, with two actors carrying a funny conversations as the main form, is called stand-up comedy. CCD is a rap art which has a comedy color. It causes the audiences to laugh with its humorous conversation and funny performance. The language of dialogue and performance, the arrangement of the plot should be both reasonable and in a way different from expected so as to achieve comic effect. Performing, learning, teasing and singing are the main means of comic dialogue art. That telling folk joke, studying the myriad things life, playing on words, provoking laughter, playing around, amusing others, acting in a Chinese opera, singing and singing song lyrics are skills that crosstalk comedians must grasp. These skills, through the exaggeration and processing of art, are used in the performance so as to create comic effect.
CCD gives priority to irony, yet in its development, new works singing the praises of new personalities and new deeds also emerge.

One of the authors of this paper, during his stay in Japan as a visiting scholar, was very startled when he found that Zhao Benshan's sketch and his song-anddance duet team performing in the US are questioned by many Chinese Americans because Zhao is very popular in the domestic performance, and is honored as "the sketch king" for many years. The author, after watching carefully the documentary film "Laughter all over the United States" performed by Zhao and his team in US online, found that while Zhao's performance was really hot on the spot, yet the online criticism of him was also objective. These two seemed very contradictory, so the author analyzed and reflected on this phenomenon conscientiously. This article, starting from the analysis of the characteristics of CCDS, regards the performance of it as a discourse to be analyzed. From the creation of the works, the actor's performance, whether the work can be accepted by the audience or not and the principle which a discourse construction needs to be consistent with, the paper draws the evaluation criteria of CCDS. 


\section{THE PRINCIPLE OF DISCOURSE CONSTRUCTIONS}

This paper, starting from the principle of discourse construction, will analyze the evaluation criteria of CCDS. Text linguists Beaugrande and Dressler [1] proposed seven standards of textuality: cohesion, coherence, intentionality, acceptability, informativity, situationality, and intertextuality. The establishment of a discourse needs to be in line with them. "Intentionality" concerns the text producer's attitude and intentions as the text producer uses cohesion and coherence to attain a goal specified in a plan; Informativity requires the discourse to express enough amounts of new information; Cohesion is a semantic one; it refers to relations of meaning that exist within the text, and that define it as a text [2]; Coherence indicts the relationship between the informative units; intertextuality can be defined simply as the relationship of a text with other texts [3], it points out the similarity in the language structure between one discourse and the others; Acceptability concerns the text receiver's attitude that the text should constitute useful or relevant details or information such that it is worth accepting. Any text, only when it is truly understood by many a listener or reader can it be a true text. Situationality concerns the factors which make a text relevant to the situation of occurrence or the discourse originate from the situation.

\subsection{Intentionality and informativity}

As intentionality and informativity have certain connection, we put them together for research.

"Intentionality" refers to the intention of those who have the intention to generate discourse, it is firstly registered as the entertainment, then according to different types of works, it manifests the promotion of rightness of the serious drama or the irony of unhealthy tendencies, evil influence of the satirical essay, which are mainly determined by the script. The comic dialogue "Corporation of theft" performed by NiuQun satirizes the institution to be overstaffing, "Concocting various pretexts" satirizes a leading cadre being spendthrift in feasting under all sorts of names, " Multi-storey hotel" performed by Ma Ji was for satirizing the low efficiency of certain organs, "Police and thief" played by Zhu Shimao and Cheng Peisi have sung the praises of police's alertness and satirized the clumsiness of the thief. The sketch "Decorating like this" acted by Huang Hong exposed some of the scenes during the barbaric decoration, "Planning", with Zhao Benshan and Niu Qun as the leading roles disclosed the problem of false advertising of television. All the above are good works of art rich in conception. There are also other works, though the performance on the spot is very hot, the audience are very satisfied, yet they can't be considered excellent works because the taste of it is in question. For example, the swindle series of sketches "Selling a crutch" with Zhao Benshan, Fan Wei , Gao Xiuming as the leading roles (including selling a crutch , selling vehicle, selling a cat). The whole works of "Selling a crutch", except that it stands out Zhao's skill in HuYou (cheating), gives people the impression that good people are easily cheated by bad guys, and they are very foolish while the swindler are both intelligent and lovely. "Selling a cat" manifests more problems. Though the "big HuYou" (Zhao) doesn't appear on the stage, yet his remaining prestige is still there, in the play, the cheated has become aware of some sort of cheating and begun to deceive someone else. But the swindler also displays he has a lot of "conscience", and deceives the others only for the protection of those who are deceived. It seems that the whole society has become a "HuYou" one, lacking in social integrity. In the piece "Little short of money", both the writer and the actors want to reflect the improved living standards of farmers and their beginning to the pursuit of higher spiritual and cultural life. But on the subject matter, it exaggerates peasants' richness level. So the work's authenticity is worth suspecting. There are also a number of comics belonging to serious drama, as far as the ideological content is concerned, there is no problem, but there is some difficulty for people to understand its comic effect.

\subsection{The principle of intertextuality, cohesion and coherence}

Due to the fact that the principle of intextuality, cohesion and coherence have some connections, we'd like to put them together for research.

The principle of intertextuality is reflected in the following: one is that the actor should select the role which is appropriate to his own characteristics, the other is that he ought to try his best to express the intention of the original work. Intertextuality plays a very important role in CCDS. The actor will achieve maximum results with little effort if he uses it wisely. Failure to using it properly will result in opposite effect. There are two sorts of relationship between the works and the actors. One is for the actor selecting the work, the other is in the writer's creating distinctive works suitable for his performance. It is quite obvious that the second method can best express the connotation of the work. For example, Zhao Benshan is the best sketch actor among the Chinese people as far as his ability in humor and making laugh is concerned. No matter what the content of the sketch is, he can amuse many people, or to be more exact, most of the audiences on the spot can do nothing but laugh, the performance effect is truly very good. So it is in America. But why is there a growing amount of 
heated discussion about him, and people's points of view are just poles apart? Take the example of the series of "Selling a crutch". In it he plays the part of a person who always "HuYou"(cheating) somebody else, and the cheated is just an ordinary honest person. In the end, there is a general tendency that the bad guy "Hu You" the good one because of his excellent acting skills. When one of the authors of this paper watched it for the first time, he really burst his sides with laughter as well as having lots of fun. But after further consideration, he felt that the sketch might miss something or there was something wrong with it. After watching the sketch "Selling a Cat", the author was finally clear about the reason. In these series of sketches, the result is almost the same, that is, the good man is always mistreated, while the bad guy is very proud of himself and begins to be corrupted by bad examples, in other words, the works' outlook on values remains questionable. From the point of view of intertextuality, such genius in making laughs as Zhao, if he is made to act as an intelligent person who is not easily to be taken in, which swindler could deceive him? In such a way, we can create series of anti-cheating sketches so as to make a great contribution to the society. For this reason, the choice of a good work suitable for the actor is the key to the success of the performance. If an actor, whose performance skills is very high but is asked to act as a villain, the result of the performance may be the good person being easily fooled by him. On the contrary, if he is made to play a good guy, it is likely that the swindler will not have a foothold.

"Cohesion" is reflected in the actors' ability to link various parts of "baofu". "Coherence" manifests the actors' faithfulness in the performance of the contents of the original script. Whether a piece of works is well linked up and whether the coherence between the "baofu" is natural lie in the following facts. One is that the works of art is well written, the other is that the actors perform well. A good actor has the ability in showing up all the "baofu" humorously and naturally. Some of the humor in the works can be deduced according to word order because there is a causal relationship between them. For example, "If a person has a big head and a thick neck, he is either a tycoon or a cook", " Stamp, and you'll have pins and needles", etc. There are also some humor having no causal relationship from beginning to end, for instance, "The eyes closed and then opened, a day has passed, the eyes closed and not opened again, a lifetime has passed.", "The painful thing in life is that a person died without spending all his money, the most torturous in life is that a person is still alive yet he has no money to spend", the utterance of the latter part of the words is beyond the audiences' expectation, so they have the feeling that it is really laughable. To "baofu" having causal relationship, the performer can finish speaking it without a break, to those that have no casual relationship, the actor had better pause for a while after finishing the former words so that the audiences can have sufficient time to think. In the end, they are exposed to unexpected result. Thus the performance can achieve the desired result and is likely to succeed. In a word, the actor's acting skill can bring about a great advance in the linking up of "baofu" in the comic dialogue and sketch.

\section{THE EVALUATION CRITERIA OF CCDS}

The author analyze the evaluation criteria of CCDS from the view of the principles of discourse construction.

\subsection{The ideological content and humor of the works}

The ideological content and humor of the works means the intentionality and informativity in the principles of discourse construction. Exquisite art originates from life and above life, which suggests that the creation of comic dialogue is very important. Without a good piece of works having a clear conception and numerous "baofu", it is really very hard for the performance to be successful if it just relies on the actors. So the creation of CCDS is the key which includes definining the subject, selecting suitable materials for the works, designing "baofu", and the content being positive and progressive as well, etc.

No matter whether it is a serious drama, a comedy or satirical CCDS, it is very easy for the creator to find a suitable content for the works either for eulogizing or satirizing it. But as far as eulogizing CCDS is concerned, it is difficult for the creator to design humorous "baofu". However, to the comedy and satirical CCDS, it is very easy for the writer to create a lot of humorous "baofu" in his works. As a result, to the serious CCDS, the excavating of laughing stock is the key for the creation of the works. However, to the comedy and satirical CCDS, the finding of a good subject is more important. Because in such pieces of works, the laughing stock is easier for the creator to find, so getting a right subject is of particular importance. The object who is to be satirized must be the correct one. If there is a mistake in finding the right person who should be satirized, it cannot be regarded as a good production even if it is rich in making laughs. For example, the series of sketches "Selling a crutch, selling a stretcher and selling a cat" which are played in the Chinese spring festival, are favorite for most Chinese audiences. But it couldn't be seen as a good series, even if it makes people laugh for a long time. Just because the conception of the works is wrong. As in this CCs, the swindler is given the praises, while the honest people are satirized. Of course, if a 
CCDS doesn't contain much "baofu" and can't make people laugh, no matter how well the conception is, we can't say it is a good works.

Therefore, whether a CCDS is a good one or not depends on the following things: the content is healthy, and there are a lot of humorous "baofu" in it.

\subsection{The scope of application of the CCDS}

The scope of application of the CCDS refers to the situationality and acceptability in the principles of discourse construction. Before a CCDS is acted, you should understand any works has its certain scope of application. If the works is beyond the special scope of application, maybe the works will be criticized by some people. For example, some works such as " Song-and-dance duet" which are popular in northeastward. However, if they are performed in South such as Shanghai, Guangzhou or Nanjing, many people will criticize the works and think the style are low or vulgar, they can't accept them. If a works is performed in CCTV Spring Festival Gala, its audiences are Chinese, even the whole world Chinese, the audiences will put forward higher requirement for the works' creation and performance.

\section{CONCLUSION}

By the above-mentioned analysis, we can get the conclusion that the evaluation criteria of a good CCDS is that:

The content of the work is correct and there are a lot of Chinese "baofu" that can make people laugh.

There is a suitable scope of application for each works. If the works shows beyond the scope of application, it may not be accepted by people.

When an actor gives people "baofu", he can use the means of artistic expression such as humorous language, body language, etc., but he can't adopt the means such as imitating disabled person or use foul language to make laugh.

\section{REFERENCES}

[1] de Beaugrande, R. \& W.Dressler. Introduction to Text Linguistics. London/New York: Longman. 1981

[2] Halliday, M. A. K. and R. Hasan. Cohsion in English. London: Longman UK group Limited. 1976

[3] Rodica Superceanu, Intertextuality and Informativity of Press Releases: Factors Determining the Communication between Practitioner and Journalist, Professional Communication and Translation Studies, 4 (1-2) / 2011 